American Journal of Environmental Sciences 5 (4): 461-467, 2009

ISSN 1553-345X

(C) 2009 Science Publications

\title{
Investigation of Vegetation Dynamics using Long-Term Normalized Difference Vegetation Index Time-Series
}

\author{
Tamara Bellone, Piero Boccardo and Francesca Perez \\ DITAG-Department of Land, Environment and Geo-Engineering, Politecnico di Torino, Italy
}

\begin{abstract}
Problem statement: The Normalized Difference Vegetation Index (NDVI) is the most extensively used satellite-derived index of vegetation health and density. Since climate is one of the most important factors affecting vegetation condition, satellite-derived vegetation indexes have been often used to evaluate climatic and environmental changes at regional and global scale. The proposed study attempted to investigate the temporal vegetation dynamics in the whole Africa using historical NDVI time-series. Approach: For this aim, 15 day maximum value NDVI composites at $8 \mathrm{~km}$ spatial resolution produced from the NASA Global Inventory Mapping and Monitoring System (GIMMS) had been used. They were derived from data collected daily by NOAA AVHRR satellites. The AVHRR NDVI GIMMS dataset was freely available and gives global coverage over an extensive time period. First of all, the selected NDVI base data had been geometrically pre-processed and organized into a historical database implemented in order to grant their spatial integration. Starting from this archive, monthly and yearly NDVI historical time-series, extended from 1982-2006, had been then developed and analysed on a pixel basis. Several routines hade been developed in IDL (Interactive Data Language programming tool) with the purpose of applying suitable statistical analysis techniques to the historical information in the database in order to identify the long-term trend components of generated NDVI time-series and extract vegetation dynamics. Specific tests had been then considered in order to define the validity of results. Results: The existence of clear regional trends of NDVI, both decreasing and increasing had been showed, which helped to highlight areas subject, respectively to reduction or increase in vegetation greenness. Conclusion: As the relationship between the NDVI and vegetation productivity was well established, these estimated long-term trend components may be also, with much more caution, related to historical and ongoing land degradation or improvement processes.
\end{abstract}

Keywords: NDVI, vegetation health, land degradation, long-term trend

\section{INTRODUCTION}

Land degradation and desertification have been major global issues during the last years particularly because of their adverse impact on agronomic productivity, the environment and their effect on food security and the quality of life ${ }^{[1,2]}$. According to Eswaran ${ }^{[2]}$, about $33 \%$ of the global 1 and surface $\left(42\right.$ million $\mathrm{km}^{2}$ ) is subject to desertification and, in particular, the semi-arid to weakly arid areas of Africa are particularly vulnerable, as they have fragile soils, localized high population densities and generally a lowinput form of agriculture.

Mechanisms that initiate land degradation include biophysical, chemical and biological processes ${ }^{[2,3]}$. Land degradation and desertification are strictly related to a reduced potential productivity or utility of plants and land, undesirable alterations in the biomass, soil deterioration, resulting from various factors, including natural or climatic variations and human activities ${ }^{[1,2,4]}$. The results, in term of economic impact of the discussed phenomena, have been very relevant in some lands of Africa, where the productivity has declined by $50 \%^{[2,5]}$, while the yield reduction has shown a mean loss of $8.2 \%$ for the whole continent ${ }^{[2]}$.

Also Agenda 21, a programmed run by the United Nations (UN) related to sustainable development, has called the attention of the international community on these issues, urging to launch several activities to solve them ${ }^{[6]}$. In this frame, a priority is to dispose of instruments and systems effective for land degradation monitoring and impact assessment and it is fundamental to develop suitable early warning indicators of land degradation and desertification.

Satellite remote sensing techniques provide successful tools for the monitoring of vegetation

Corresponding Author: Francesca Perez, DIGAT-Department of Land, Environment and Geo-Engineering, Politecnico di Torino, Italy Tel: +39-011.1975.1871 
productivity and ecosystems, due to the availability of several data with different spatial, temporal and spectral resolutions. The various data sources available through remote sensing offer the possibility of gaining environmental data over both large areas and relatively long time-periods (about three decades of satellite acquisitions). Moreover, satellites provide images of the same area in different times, allowing change detection analyses on land susceptibility to degradation. Particularly, in order to monitor vegetation dynamics and productivity over a long time scale and on a large spatial scale, a fundamental base data is constituted by several vegetation indicators derived from satellite imagery $^{[7]}$.

The NDVI (Normalized Difference Vegetation Index) is the most commonly used satellite derived index of vegetation health and density used in this field. The NDVI has shown consistent correlation with vegetation biomass and vegetation dynamics in various ecosystems worldwide. As reported by several authors, the relationship between the NDVI and vegetation productivity is well established; the NDVI has been shown to be related to biophysical variables that control vegetation productivity, such as the leaf-area index, the fraction of photo-synthetically-active radiation absorbed by vegetation and Net Primary Productivity (NPP) ${ }^{[1,8-10]}$. Thus, this index could be used in order to detect and measure land degradation processes, that may be defined as a long-term loss of ecosystem function and productivity and that may be measured by changes in NPP ${ }^{[10]}$.

As a matter of fact, in this frame, it exists an extensive collection of international studies about land degradation/desertification and vegetation monitoring using remote sensing techniques. An interesting review of several experiences, conducted at a large scale, nationally and sub-continentally and using long timeseries of satellite derived NDVI as the basis for assessment, can be found in the Gibson's work ${ }^{[11]}$. For example, relevant studies using long-term satellite derived NDVI as an indicator of land degradation, have been done in West Africa ${ }^{[12,14]}$ and in the Eastern Mediterranean region ${ }^{[13]}$.

Of course, some limits to the use of vegetation indices have to be taken into consideration. The NDVI is affected by different deficiencies due to sensitivity to soil color, atmospheric effects, illumination and observation geometry. Nevertheless, it is the most widely used vegetation index by the research community. The reason of this is that the development of different vegetation indices, for example the SoilAdjusted Vegetation Index (SAVI), the Modified SoilAdjusted Vegetation Index (MSAVI), the
Atmospherically Resistant Vegetation Index (ARVI) and the Enhanced Vegetation Index (EVI) have not resulted in the creation of a consistent long-term time series of data ${ }^{[12]}$.

In this study we propose the first results of a study aimed at investigating, with proper robust statistical techniques, the temporal vegetation dynamics in the whole Africa using historical NDVI time-series. Obtained outcomes of this study have been used in order to define monitoring procedures suitable to drought early warning activities, developed for the Information Technology for Humanitarian Assistance, Cooperation and Action (ITHACA) association.

The observed trends in analysed historical series can help to describe long-term vegetation dynamics and to highlight areas subject to the increase or reduction in vegetation greenness. Moreover, as the relationship between the NDVI and vegetation productivity is well established, these estimated long-term trend components may be also, with much more caution, related to historical and ongoing land degradation or improvement processes. Particularly, to correctly interpret NDVI trends in terms of land degradation or improvement, attention must be paid to climatic variability and land use change factors ${ }^{[10]}$.

\section{MATERIALS AND METHODS}

The NDVI is the most extensively used satellitederived index of vegetation health and density and it is defined as:

$$
\mathrm{NDVI}=\left(\rho_{\mathrm{NIR}}-\rho_{\mathrm{RED}}\right) /\left(\rho_{\mathrm{NIR}}+\rho_{\mathrm{RED}}\right)
$$

where, $\rho_{\text {NIR }}$ and $\rho_{\text {RED }}$ are the reflectance's in the nearinfrared and red bands captured by the satellite sensor. In theory, NDVI measurements range between -1 and +1 ; however, in practice, the measurements generally range between -0.1 and +0.7 . Clouds, water, snow, ice and non-vegetated surfaces have negative NDVI values. The NDVI values for vegetation are positive and range from 0.3-0.7, with low values indicating poor vegetation conditions and possibly unfavourable weather impacts.

Different NDVI datasets, derived from satellite, are available, with different spatial and temporal resolutions and different temporal coverage. In this study, 15 day maximum value NDVI composites at 8 $\mathrm{km}$ of spatial resolution produced by the NASA Global Inventory Mapping and Monitoring System (GIMMS) at NASA's Goddard Space Flight Center have been used $^{[12,15]}$. They are derived from data collected daily by the Advanced Very High Resolution Radiometer 
(AVHRR) instrument on board of the National Oceanic and Atmospheric Administration (NOAA) polar orbiting satellite series. The base data have been corrected by GIMMS to minimize cloud contamination using Maximum Value Compositing (MCV). Furthermore, the final GIMMS NDVI dataset is corrected for sensor degradation and inter-calibration differences, global cloud cover contamination, viewing angle effects due to satellite drift, volcanic aerosols and low signal-to-noise ratios due to sub-pixel cloud contamination and water vapor ${ }^{[16]}$. The effect of these issues have been removed with a correction using Empirical Mode Decomposition (EMD) designed for non-parametric and non-stationary data, resulting in a stable time-series, relatively consistent over time, appropriate for trend analysis ${ }^{[17]}$. Finally, the AVHRR NDVI GIMMS dataset is freely available and gives global coverage over an extensive time period (1981 to present).

In particular, a fortnightly NDVI time-series for the period 1982-2006 was taken into consideration. First of all, for the purposes of the proposed study, the selected NDVI base data have been geometrically pre-processed and organized into a suitable historical database implemented in order to grant their spatial integration. Starting from this archive, monthly NDVI historical time-series, extended from 1982-2006, have been then developed and analyzed.

First of all, simple smoothing techniques (moving average based techniques) have been applied to these generated NDVI time-series. Smoothing of a timeseries is a statistical procedure used to dampen out the fluctuations in order to obtain a more regular series. This operation is designed to remove the random component, leaving behind the systematic component in the series and it often helps to uncover underlying patterns. After that, new monthly and yearly NDVI time-series have been constructed. Several routines have been then implemented in IDL (Interactive Data Language programming tool) with the purpose of applying suitable statistical analysis techniques to the historical information in the database to perform a components analysis in order to discover underlying patterns in generated time-series and extract the desired vegetation dynamics.

In particular, using proper statistical methods (Least Square regression techniques, LS, which are very sensitive to outliers in real data, coupled with a robust technique, such as Least Median of Squares regression estimator, LMS, used for a preliminary outliers detection and removal), the parameters of the regression have been calculated in order to show the NDVI trends. As aforementioned, NDVI data are often affected by noise arising from different sources, including clouds, atmospheric perturbations and variable illumination and viewing geometry. All of these factors usually reduce NDVI values. For the purposes of this study the presence of residual contaminations in used time-series, due to these effects, has been considered. Therefore, to have recourse to a proper outliers detection technique has been regarded a preliminary and fundamental step in the carried out analyses.

In particular, when we use least square methods, we assume some well known hypotheses, namely about the vector of errors. Actually, the said assumptions are not always observed. Heavier-tailed distributions may generate larger errors than the normal ones do: robust techniques are proper in this case. A number of methods are available, starting with the $\mathrm{L}_{1}$ norm (Laplace-Bošković). Some of them are able to check even $25 \%$ of outliers ${ }^{[21]}$; others ${ }^{[20]}$, as $\mathrm{M}$ methods, can detect not only outliers, but also the leverage points (till $30 \%)$.

The LMS method is different from the previous ones in what concerns the breakdown point and the computational algorithm. Indeed, this method has a high break-down point (about 50\%); moreover, it allows computation of the solution chosen after checking among all other possible solutions, drawn from combinations of available values, once an optimization criterion has been established: the solution produces the minimum median of squared residuals ${ }^{[18,19]}$. The calculation is as follows:

$$
\operatorname{median}\left(\mathrm{NDVI}_{\mathrm{i}}-\mathrm{NDVI}_{\mathrm{i}}\right)=\min
$$

where, $\mathrm{NDVI}_{\mathrm{i}}, \mathrm{NDVI}_{\mathrm{i}}$ are, respectively, the observed NDVI value and the estimated one.

In practice, for any given vector $\mathrm{x}$ of estimates, we could find the median of squared residuals: The solution is that $\mathrm{x}$ that produces the minimum median.

In this study, the LMS method has been used for robust data snooping: Identification of outliers makes easier reconnaissance of elements due to other distributions. Moreover, detected outliers may also reveal anomalies of NDVI values; properly treated, they could be used as warnings revealing anomalies in ongoing vegetation conditions that can be used for drought detection and near real-time monitoring purposes. This hypothesis requires to be validated, verifying the significance of detected outliers according to historical drought events or historical precipitation anomalies. 
After the robust data snooping phase, a reestimation of regression, deprived of outliers, has been performed. The slope of regression was finally verified by the Student's t test, around zero values:

$$
\mathrm{H}_{0}: \mathrm{E}[\hat{\mathrm{a}}]=0\left|\frac{\hat{\mathrm{a}}}{\sigma_{\hat{\mathrm{a}}}}\right| \leq \mathrm{t}_{\alpha / 2, v=\mathrm{m}-2}
$$

where, $\hat{a}$ is the slope of regression.

\section{RESULTS}

During a preliminary vegetation analysis, several NDVI measures (such as minimum, maximum and mean NDVI values, standard deviation and coefficient of variation) have been calculated for each year (from 1982-2006) and investigated. Figure 1 and 2 show some results of this preliminary analysis.

Figure 1 shows the spatial pattern of long-term mean values of yearly NDVI.

The annual variability of monthly NDVI values with respect to the mean annual value has been evaluated for every year and for every pixel and its temporal change during the 25 years observation window, has been investigated using the Coefficients of Variation (CoVs). As a matter of fact, the use of the coefficients of variation allows to evaluate and compare the spatial distribution of the annual variability of monthly values on a pixel basis. Figure 2 shows the distribution of the long-term (1982-2006) mean coefficients of variation of NDVI values; it helps to identify the areas where the vegetation has been subject to the major changes during the observed 25 years.

The complete trend components estimate (LS coupled with LMS methods) has been carried out starting from monthly and yearly NDVI time-series using a pixel-based level of spatial data aggregation. Thus, the behaviour of NDVI time-series has been analysed for every single cell $\left(8 \times 8 \mathrm{~km}^{2}\right)$. The spatial distribution of the slopes of the regressions, obtained analyzing yearly and monthly time-series, are presented in Fig. 3-5. According to the aforementioned hypotheses, white and dark grey areas show, respectively, reduction or increase in vegetation greenness between 1982 and 2006; while light grey areas have not been subject to significant vegetation changes, according to the implemented Student's t test. Finally, Fig. 6 shows an example of results obtained during the data snooping phase performed using monthly NDVI time-series: Spatial distribution of the detected outliers for the month of April 2004. NDVI values that belong in light grey areas are those that have been used for LS regression.

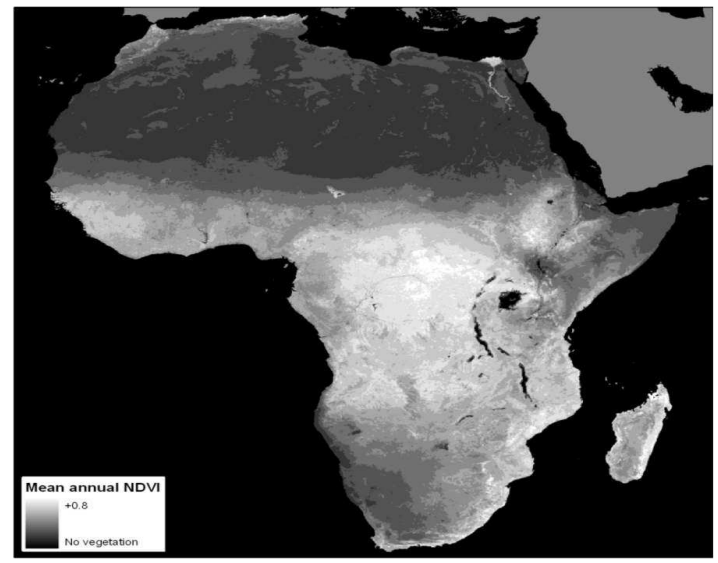

Fig. 1: Spatial distribution of long-term (1982-2006) mean values of yearly NDVI

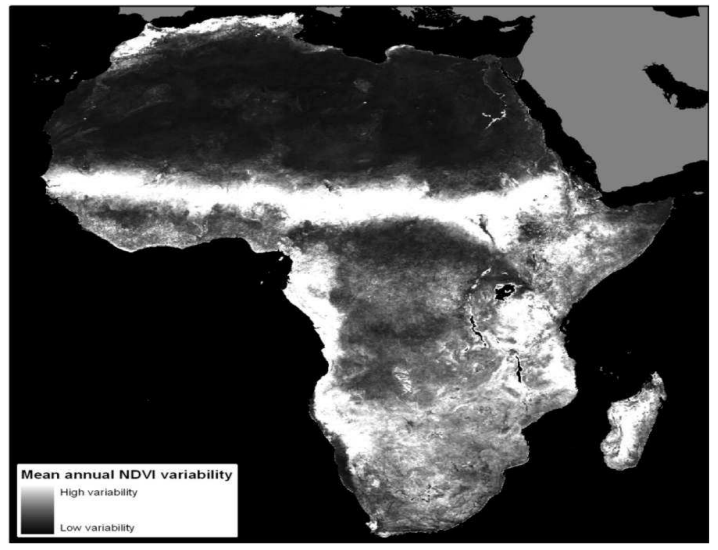

Fig. 2: Spatial distribution of long-term mean values of yearly Coefficients of Variation (CoVs)

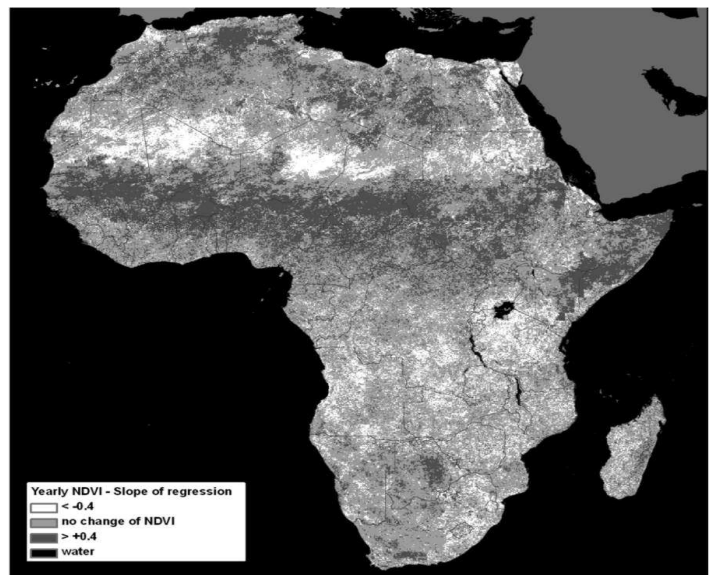

Fig. 3: Overall trends in vegetation greenness for the period 1982-2006: Spatial distribution of slopes of the regressions for yearly NDVI values 


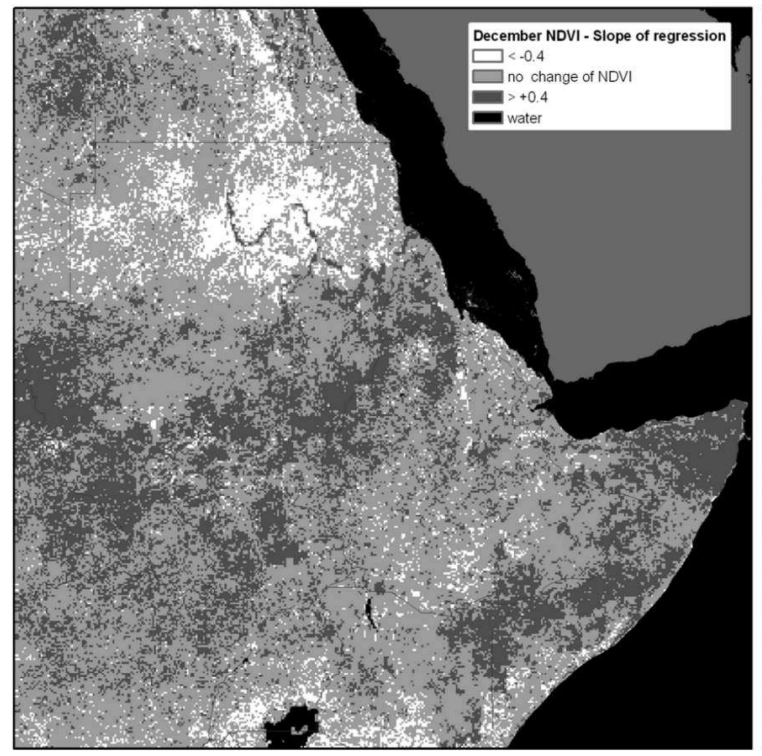

(a)

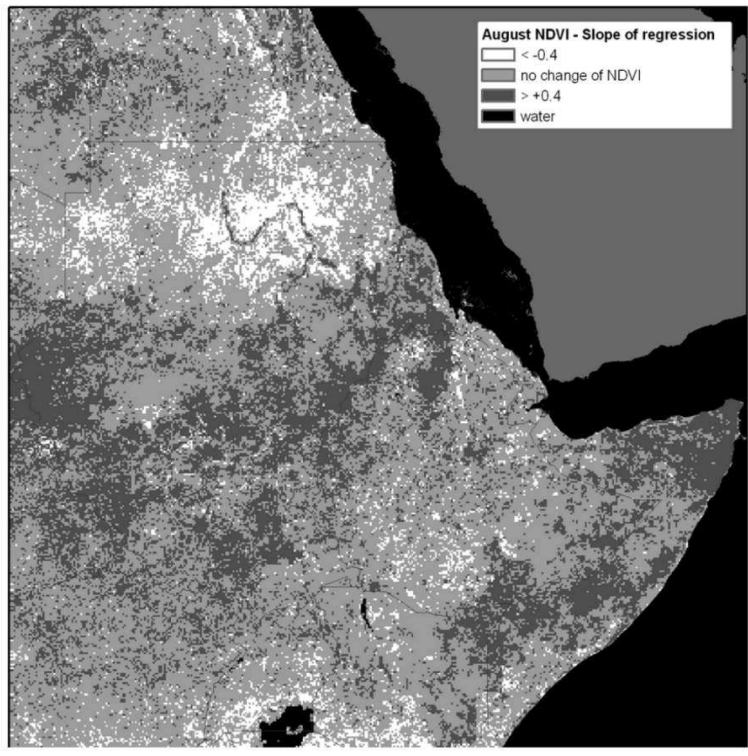

(b)

Fig. 4: Overall trends in vegetation greenness for the period 1982-2006: Spatial distribution of slopes of the regressions for monthly NDVI values (December and August trends, Horn of Africa area)

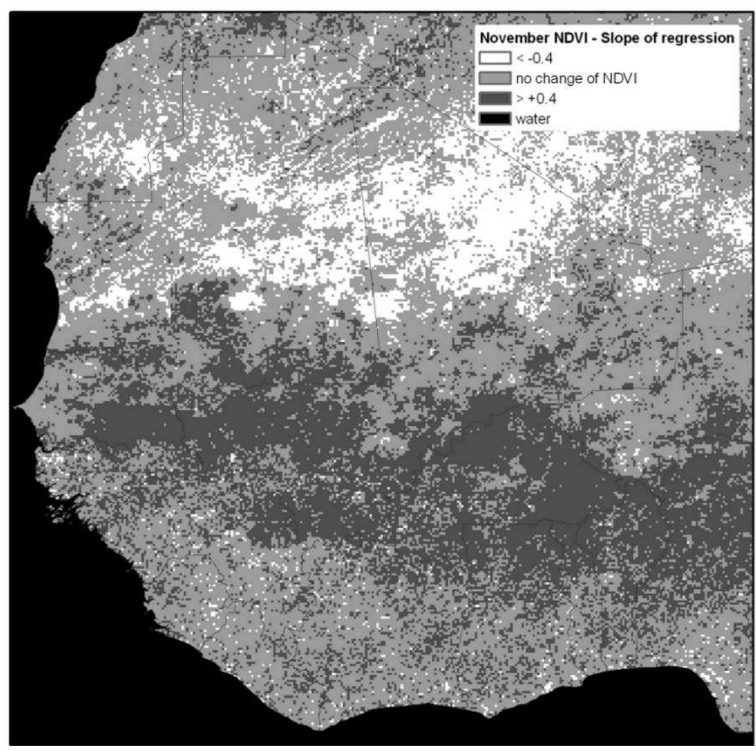

(a)

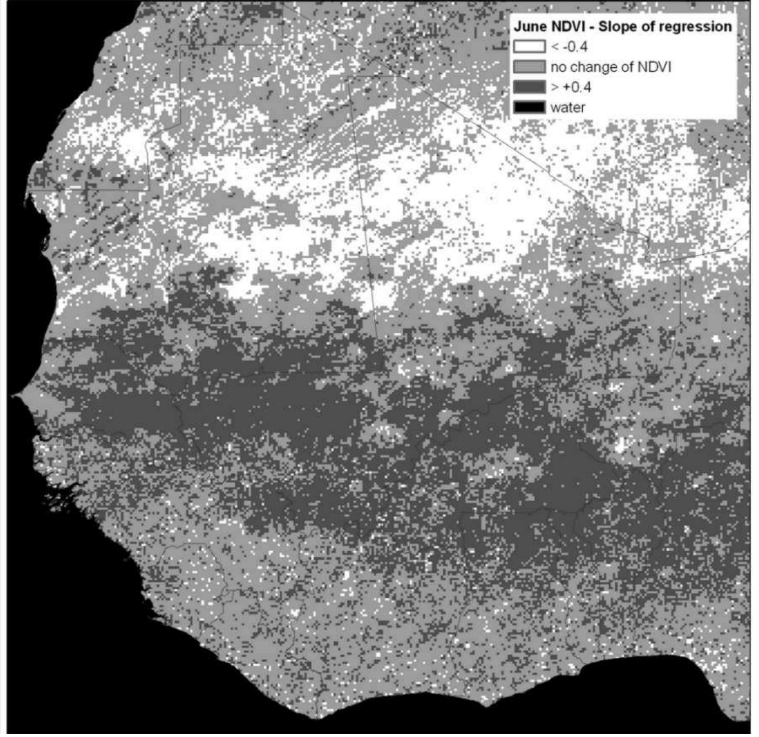

(b)

Fig. 5: Overall trends in vegetation greenness for the period 1982-2006: Spatial distribution of slopes of the regressions for monthly NDVI values (November and June trends, West Africa area)

\section{DISCUSSION}

The results of this study show the existence of clear regional trends of NDVI over the period 1982-2006, both decreasing and increasing, which can help to describe long-term vegetation dynamics and to highlight areas subject, respectively, to reduction or increase in vegetation greenness and biomass production. Moreover, it can be noticed that the robust methodology applied in this study, allowing to detect and remove residual noise data in base time-series before the estimation of the trend components, guarantees effective results. 


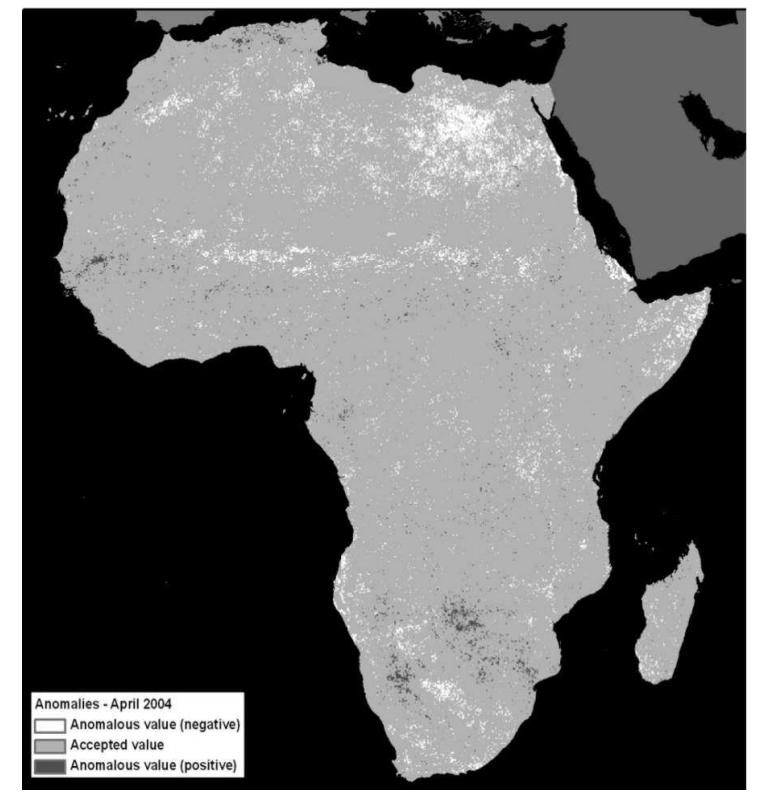

Fig. 6: Spatial distribution of the detected outliers for the month of April 2004

Obtained results are confirmed, in spite of some disagreements due firstly to the use of different methodologies, by the results of studies proposed by other authors. For example, a significant greening of the Sahel expressed in positive trends in NDVI, indicating a net increase in biomass production, were noted by Herrmann et al. ${ }^{[12]}$. Besides, a more general agreement can be found with Bay et al. ${ }^{[10]}$.

Moreover, obtained greening trends are not uniform. Thus, further study developments are based on the investigations of the factors that may have contributed to this differential response. In particular, some regions of Africa showed a unstable behavior over the period 1982-2006 (for instance, the Sahel zone in Fig. 2). Therefore, from a more proper statistical treatment of these areas, a piecewise regression seems at present advisable and we shall deal with it in the near future. The process is as follows:

- Once the first outlier has been found, a least square fitting is performed for all points until the last one

- Starting with the outlier, we go onward with the robust data snooping (least median of squares method)

- As the second outlier has been detected, the least square fitting is performed for the second section and so on

The real advantage of this process will be better shown in a future application.

\section{CONCLUSION}

As already discussed, the actual meaning on the ground of greening has not yet been firmly established. Therefore, the observed greening trends may be interpreted as land degradation or improvement with much caution. For these purposes, the identified patterns of vegetation degradation and improvement identified need to be further explored by comparisons with climatic, land cover, soil and terrain and socioeconomic data, using also field survey data on dominant rural activities at local scale and, perhaps, finer resolution satellite data.

Of course, the obtained NDVI trends may simply help to identify areas subject to vegetation degradation phenomena that may imply reduction in biomass, decrease in species diversity, or decline in quality in terms of the nutritional value for livestock and wildlife $^{[2]}$.

\section{ACKNOWLEDGMENT}

The researchers wish to tank the NASA Global Inventory Mapping and Monitoring System (GIMMS) at NASA's Goddard Space Flight Center for providing the AVHRR NDVI dataset.

\section{REFERENCES}

1. Tagil, S., 2007. Monitor land degradation phenomena through landscape metrics and NDVI: Gordes, kavack, ihcak, kumcay and marmara lake basin (Turkey). J. Applied Sci., 7: 1827-1842. http://scialert.net/abstract/?doi=jas.2007.1827.1842

2. Eswaran, H., R. Lal and P.F. Reich, 2001. Land degradation: An overview. http://soils.usda.gov/use/worldsoils/papers/landdegradation-overview.html

3. Lal, R., 1993. Tillage effects on soil degradation, soil resilience, soil quality and sustainability. Soil Tillage Res., 27: 1-8. DOI: 10.1016/01671987(93)90059-X

4. Dregne, H.E., 1986. Desertification of Arid Lands. In: Physics of Desertification, El-Baz, F. and M.H.A. Hassan (Eds.). Dordrecht, Netherlands, ISBN: 9789024732920, pp: 4-34.

5. Dregne, H.E., 1990. Erosion and soil productivity in Africa. J. Soil Water Conserv., 45: 431-436. http://cat.inist.fr/?aModele $=$ afficheN\&cpsidt $=19355820$

6. Division for Suitable Development, 1993. Agenda 21: Earth summit-the United Nations programmed of action from Rio.

http://www.un.org/esa/sustdev/documents/agenda2 1/english/agenda21 toc.htm 
7. Hassan, I.M.E., 2004. Desertification monitoring using remote sensing technology. Proceeding of the International Conference on Water Resources and Arid Environment, (CWRAE'04), Saudi Arabia, pp: 1-15.

http://www.psipw.org/English_PDF/3_Distance/E3 $-3 . p d f$

8. Pettorelli, N., J.O. Vik, A. Mysterud, J.M. Gaillard, C.J. Tucker and N.C. Stenseth, 2005. Using the satellite-derived NDVI to assess ecological responses to environmental change. Trend. Ecol. Evolut., 20: 503-510. DOI: 10.1016/j.tree.2005.05.011

9. Running, S.W., R. Ramakrishna, R. Nemani, F.A. Heinsch, M. Zhao, M. Reeves and H. Hashimoto, 2004. A continuous satellite-derived measure of global terrestrial primary production. Bioscience, 54: $\quad 547-560$. DOI: $10.1641 / 0006-$ 3568(2004)054[0547:ACSMOG]2.0.CO;2

10. Bai, Z.G., D.L. Dent, L. Olsson and M.E. Schaepman, 2008. Global assessment of land degradation and improvement 1: Identification by remote sensing. Report 2008/01.

http://www.fao.org/nr/lada/dmdocuments/GLADA _international.pdf

11. Gibson, D.J.D., 2006. Land degradation in the Limpopo Province, South Africa. Master of Science degree.

http://witsetd.wits.ac.za:8080/dspace/bitstream/123 456789/2137/1/Dissertation-031006-final.pdf

12. Herrmann, S.M., A. Anyamba and C.J. Tucker, 2005. Recent trends in vegetation dynamics in the African Sahel and their relationship to climate. Global Environ. Change, 15: 394-404. http://www.fao.org/nr/lada/dmdocuments/Herrman n_Anyamba_Tucker_GEC_20051.pdf

13. Udelhoven, T., T. Jarmer, B. Katlan, M. Al-Abed, N. Assad, Z. Makhamreh and J. Hill, 2005. Surface degradation and recovery indicators in the eastern Mediterranean region derived from long-term monthly $1 \mathrm{~km}$ AVHRR/NDVI data. Proceeding of the 1 st International Conference on Remote Sensing and Geoinformation Processing in the Assessment and Monitoring of Land Degradation and Desertification, 2005, Trier, Germany, pp: 239-246.
14. Olsson, L., L. Eklundh and J. Ardoe, 2005. A recent greening of the Sahel-trends, patterns and potential causes. J. Arid Environ., 63: 556-566. http://cat.inist.fr/?aModele $=$ afficheN\&cpsidt $=1706$ 6356

15. Tucker, C.J., J.E. Pinzon, M.E. Brown, D. Slayback, E.W. Pak, R. Mahoney, E. Vermote and N. El Saleous, 2005. An extended AVHRR $8 \mathrm{~km}$ NDVI data set compatible with MODIS and SPOT vegetation NDVI data. Int. J. Remote Sens., 26: 4485-5598. DOI: $10.1080 / 01431160500168686$

16. Tamavsky, E., S. Garrigues and M.E. Brown, 2008. Multiscale geostatistical analysis of AVHRR, SPOT-VGT and MODIS global NDVI products. Remote Sens. Environ., 112: 535-549. http://cat.inist.fr/?aModele $=$ afficheN\&cpsidt $=2000$ 6134

17. Brown, M.E., J.E. Pinzon and C.J. Tucker, 2004. New vegetation index dataset available to monitor global change.

http://gimms.gsfc.nasa.gov/Molly/pdf_files/EOS_S ubmission_v2.pdf

18. Rousseeuw, P.J., 1984. Least median of squares regression. J. Am. Stat. Assoc., 79: 871-880. http://www.jstor.org/stable/2288718

19. Rousseeuw, P.J. and A.M. Leroy, 1987. Robust Regression and Outlier Detection. 1 Edn., WileyInterscience, New York, USA., ISBN: 0-47185233-3, pp: 329.

20. Hampel, F.R., E. Ronchetti, P.J. Rousseeuw and W.A. Stahel, 1986. Robust Statistics: The approach Based on Influence Functions. Wiley-Interscience, New York, USA., ISBN: 0-471-82921-8, pp: 85-101.

21. Huber, P., 1981. Robust Statistics. 1st Edn., Wiley, New York, USA., ISBN: 0471418056, pp: 320. 